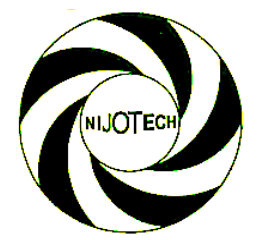

Nigerian Journal of Technology (NIJOTECH)

Vol. 38, No. 3, July 2019, pp. 707 - 715

Copyright@ Faculty of Engineering, University of Nigeria, Nsukka,

Print ISSN: 0331-8443, Electronic ISSN: 2467-8821

wWw.nijotech.com

http://dx.doi.org/10.4314/njt.v38i3.24

\title{
ADOPTABILITY OF ELECTRONIC DOCUMENT MANAGEMENT SYSTEM IN ILORIN BUSINESSES
}

\author{
N. A. Balogun', L. A. Raheem ${ }^{2}$, M. D. Abdulrahaman ${ }^{3, *}$ and U. O. Balogun ${ }^{4}$ \\ 1, 3, DePT. OF INFORMATION \& COMMUNiCATION SCIENCE, UNIV. OF ILORIN, ILORIN, KWARA STATE, NIGERIA. \\ 2, SOCIETY FOR YOUTH EMPOWERMENT IN NigERIA, GWARIMPA, ABUJA, NIGERIA. \\ 4, KEYSTONE BANK LIMITED, VICTORIA ISLAND, LAGOS, LAGOS STATE, NIGERIA. \\ E-mail addresses: ${ }^{1}$ naeem.ab@unilorin.edu.ng, ${ }^{2}$ adedlamina@gmail.com, \\ 3 rahaman.md@unilorin.edu.ng, 4 ussybaloo83@yahoo.com
}

\begin{abstract}
Electronic Document Management System (EDMS) is an automated solution that improves organization workflow and competitiveness. Despite the enormous benefits derived from its implementation, some organizations have not exploited the opportunities. This study examines the factors that affect adoption and non-adoption of EDMS. An interpretive research approach was employed through an in-depth interview of IT officers and record managers at some public and private organizations within Ilorin metropolis using purposive sampling technique. The result of the data analysis using deductive coding frame of Atlas revealed some themes that were crosstabulated or mapped with some information systems models. It was revealed that search functionality, reliability, accessibility, and security of EDMS, are the major reasons for adoption, while reasons for non-adoption include vulnerability to attack, high cost of implementation and digital illiteracy of staff members. It was recommended that open source development of the system be encouraged to ensure exclusive adoption by organizations.
\end{abstract}

Keywords: Electronic_Document_Management_System, EDMS, ICT in Business, Ilorin Businesses, Document Management

\section{INTRODUCTION}

In recent years, the advancement of technology has enhanced handling and delivering of services in many aspects of our lives such as businesses, governance, industrialization, socialization, and communication. Specifically, Information Technology is regarded as a game changer, and a catalyst that improves accessibility to information and services [1]. Business organizations either large or small use information to conduct their day to day activities and making necessary decisions regarding employees, customers, associates, goods, services, and investments. Most of the business related information are regarded as records and usually kept in form of documents, prepared, stored and used in various data format, depending on the nature of the work, entities involved and requirements. These, thereby, making document management a necessity for the survival of businesses.

Decade ago, business records are stored and managed on paper, usually regarded as a manual approach. This manual based approach is characterized by lots of inefficiencies and work related issues like high time consumption, errors and redundancy during information collection, storage, and retrieval [2]. Due to the dynamic nature of modern businesses that require enterprises maintaining electronic documents in order to ensure interoperability of services, compete favorably, and share information seamlessly, it is necessary for all business related information to be collected, stored, retrieved, and shared in a digital form [2]. Electronic Document Management System (EDMS) is an automated system that supports the creation, storage, usage, retrieval, and maintenance of documents or records in both paper and electronic

\footnotetext{
* Corresponding author, tel: +234- $703-610-9019$
} 
formats with the primary intention of improving the workflow and processes of an organization effectively [3]. It is sometimes referred to as Electronic Document and Record Management System (EDRMS).

The enormous advantages provided by EDMS to organizations in term of reduction in operational cost, speed information access and record retrieval, make it a widely accepted tool among public and private organizations including government Ministries, Departments and Agencies (MDAs) across the world. EDMS has been a huge success in various fields of business, through the cutting of costs, increase in productivity and implementation of a streamline workflow process. As a result, many organizations have moved from the paper based model that is characterized by human error and slow retrieval process, to a paper-less system and retrieval efficiency that has yielded bountiful results. EDMS increases organization's control access to documents, provides additional security and privacy, and ensuring flexibility in the access to information anywhere at any time [4]. With an efficient electronic document management system, organization can quickly and painlessly profile its new information in ways that make it accessible exactly when and where it is needed. The organization's options for profiling and organizing documents are virtually infinite.

Despite the importance of EDMS to improving workflow and business processes that has made many governments and organizations invest heavily on it, some organizations or individuals still don't use it or have no intention of using it at all. Over the decades, the level of technology adoption has risen across the world including the developing nations. Several studies have been done to examine the adoptability of EDMS among government establishments [3, 5], but few empirical studies have been carried out to ascertain the level of EDMS adoption among businesses, especially in the developing countries. Therefore, this research work sought to provide insight in the area of Electronic Document Management System adoption in Ilorin businesses, the state capital of Kwara State of Nigeria. The study also sought to find the underlying reasons why businesses opt to use the manual paper filing system that is so riddled with human inefficiencies and retrieval problems despite the enormous benefits with the use of EDMS.

\section{LITERATURE REVIEW}

\subsection{Review of related concepts}

Historically, Information Technology development can be classified into three phases. First, the automate phase where the implementation of IT solution was to reduce the labor requirement for the manual aspect of clerical work which resulted into significant reduction in the time and cost required to manually perform some routine and tedious works, as well as improving in service delivery. Example of the systems in this category is a payroll system, which is one of the systems generally referred to as "Transaction processing System" [6]. Second, the information management phase, where several computer applications are employed for the purpose of performing extensive and effective management functions and controls. A popular application in this category includes management information system (MIS). The third is known as transformation phase, where IT solutions are employed to transform the means of business transaction through web and networking environments such as internet, local area network (LAN), cloud computing and mobile technology. The category of systems that fall here are referred to as strategic information system (SIS) where EDMS belong [6]. However, the reality of the day has mandated every modern business to exploit all the phases of IT development in order to compete favorably and share information among their associates.

According to [3], Electronic Document Management System is defined as an automated system that supports the creation, collection, usage, and maintenance of documents and records in both paper and electronic forms with the intention of improving the efficiency of an organization. EDMS can also be defined as an application of technology for the purpose of saving paper, speed up communication and workflow, and increasing the productivity of business processes [5]. EDMS is an important aspect of businesses and inter-governmental services that encourages interoperability, and bring about synergy between internal and external organizations [1]. Some of the features of a typical EDMS include security enhancement, interoperability of organizations, document and record efficiency management and improvement, space, time and cost efficiency, reduction, flexibility and ease of information access as well as accountability. EDMS enables organizations manage documents throughout the information lifecycle including creation and destruction. Some of 
the electronic document management technologies are; document imaging, internet, hypermedia, computer aided design/ manufacturing, website, Extensible Markup Language (XML), Generalized Markup language (GML) [7]. In most cases, an EDMS functions as a quick information retrieval, groupware, workflow and knowledge manager [8].

\subsection{Review of related works}

Several studies have been conducted in an attempt to examine the adoptability or acceptance level of electronic document management system in different domains of public and private sectors across the world. For instance, [3] developed a conceptual model to investigate the determining factors that impact the adoption of electronic document and record management system in the public sector of Malaysia. A qualitative approach was used by performing content analysis of research article from reputable academic databases and followed by the adoption of Unified Theory of Acceptance and Use of Technology (UTAUT) as a research framework. The authors extracted 6 variables including performance expectancy (PE), Effort expectancy (EE), Social Influence (SI), Facilitating Conditions (FC), perceived value of Records (PVR) as well as the Perceived Risks. The three variance of Risks used are performance risk, privacy risk, and overall risk, while Age, Gender, and Position Grade were considered as moderators. However, the proposed framework was based on literature reviewed and has not been subjected to real life test to determine its appropriateness in the public sector.

In [5], the authors examined the effect of a set of antecedent factors on the intention of users to accept EDMS using Theory of planned Behavior (TPB) as theoretical framework. The study collected a quantitative data from a sample of 186 National Tax Administration (NTA) users of real e-Government's EDMS in Taiwan out of 450 people who had previously used the system. The data was analyzed with Structural Equation Modeling (SEM) of AMOS 5.0 software. The result of the analysis strongly supported the predictive ability of TPB to predict user's intention to accept EDMS. The findings also revealed perceive ease of use; perceive usefulness; training; compatibility; external influence; interpersonal influence; facilitating condition; and self-efficacy as the main determinants of EDMS acceptance. Policy makers in government and organizations are advised to be providing adequate training for users in order to motivate them towards the use of EDMS.

Similarly, Wijaya [1] examined factors that influence the user adoption of an electronic document management system with an emphasis on an application named "Sistem Informasi Aplikasi Persuratan (SIAP)". The study adopted Technological Acceptance Model (TAM) to examine the individual traits such as social influence, facilitating condition, self-efficacy, and user training as external variable. The study sampled a total number of 106 respondents at Audit Board of the Republic of Indonesia and analyzed the collected data using co-variance based SEM aided by AMOS 21. The result of their quantitative research collected through email and online forms shows that social influence, user training, and selfefficacy have positive impacts on perceive usefulness and perceive ease of use which in turn affects intention to use the system. It also shows that social influence, self-efficacy and user training to have key roles in determining users' intention to use. Finally, it shows that perceived usefulness and ease of use are important factors in motivating users to use an EDMS application.

Reference [6] conducted a qualitative research to investigate the implementation of an organizationalwide EDMS through a case study analysis of the employees of United Kingdom Local Authority (UKLA). The research revealed that EDMS deployment involves high risk, expensive to acquire, and require high revenue stream. It implementation requires feasibility study, commitment of the senior management, regular training, and alignment with the business strategy. Reference [7] investigated how to identify and evaluate document genres of industrial organizations that are producing complex high-tech products. The study revealed that electronic document management (EDM) is not popular in the manufacturing industry and recommend an industrial specific system rather than a generic one. The study conducted by [9] examined the adoption of EDMS for civil court management with focus on four applications namely, electronic filing system (EFS), case management system (CMS), court recording and transaction (CRT), and Queue management system (QMS) in Malaysia courts. An interpretive research approach was adopted with exploratory case study at the civil court in Kuala Lumpur and Putrajaya. The study shows that the implementation of court management system, an example of EDMS, has improved judicial system significantly in Malaysia. 


\section{RESEARCH METHODOLOGY}

An interpretive research approach was employed through an in-depth interview session at premises of four organizations including two in public sector (Federal Inland Revenue service, and Kwara State Ministry of Communication and Information) and two in private sector (E-Phoenix Hotels and tourism and Dool-x funtastix). The four organizations were selected based on purposive sampling technique. The interpretive research approach was chosen because it does not depend on predefined dependent and independent variables, but focuses on the complexity of human sense making as the situation emerges [7]. A total number of eight (8) respondents, two (2) from each organization were selected for interviews, using a structured interview guide for delivering the questions to be asked. The interviewees were IT officers or ranked officers that are knowledgeable about document management of their respective organizations. This was to ensure that the responses gathered are most relevant to the research study.

Finally, Atlas. It software was used to analyze the transcribed responses of the participants by applying "deductive coding frame" features to extract code frequencies from interviewees' comments. The emerged codes (factors or themes) are then correlated or mapped with the technology adoptability factors (variables) of some already established information systems' acceptance or adoption frameworks such as Technology Acceptance Model (TAM), Unified Theory of Acceptance and Use of Technology (UTAUT), and Theory of Planned Behavior (TPB). This is to confirm the appropriateness of the interpretive research approach in determining the adoptability of EDMS and other information systems.

\section{ANALYSIS AND RESULTS}

This section presents the demographic description of interviewees and various codes that emerged after the transcribed responses were thoroughly analyzed using deductive coding frame analysis feature of Atlas, a qualitative data analysis (QDA) software.

\subsection{Demographic Profile of Respondents}

As presented in table 1, a total number of eight (8) respondents were interviewed, out of which two (2) are from each of the four (4) organizations sampled. The result shows that five (5) of the interviewees are male and three (3) are female which represents a distribution of $62.5 \%$ and $37.5 \%$ respectively. It also revealed that one of the interviewees is less than 20 years of age, while four are between the ages of 21 40, and three are 41 years above. Table 1 also describes the education levels and ranks of the respondents. It shows that two respondents did not attend or graduate from higher institution, while six graduated from higher institutions. Finally, from our sample, four of the interviewees are IT officers, three (3) are record managers, while one (1) is ranked as others such as secretary.

Table 1: Demographic Profile of Respondents.

\begin{tabular}{ccc}
\hline Description & Respondent & Percentage \\
\hline & Gender \\
\hline Male & 5 & 62.5 \\
Female & 3 & 37.5 \\
\hline \multicolumn{3}{c}{ Age } \\
\hline Less than 20 years & 1 & 12.5 \\
21 - 40 years & 4 & 50 \\
41 years - Above & 3 & 37.5 \\
\hline \multicolumn{3}{c}{ Education } \\
\hline Non-Graduate & 2 & 25 \\
Graduate & 6 & 75 \\
\hline \multicolumn{2}{c}{ Rank } \\
IT officer & 4 & 50 \\
Record manager & 3 & 37.5 \\
Others & 1 & 12.5 \\
\hline
\end{tabular}

\subsection{Analysis of interview responses}

In order to identify the themes that determine the reasons for the adoption and non-adoption of EDMS in the sampled public and private business organizations, an "open coding system" was used under the following themes:

Major Theme 1: Reasons for the adoption of Electronic Document Management Systems.

The codes that make-up this theme include "Reasons for the use of EDMS", "Cost effectiveness" and "Drawbacks to using manual document management" as shown in Figure 1.

Based on the questions asked to elicit the reasons for the adoption of EDMS, the most dominant reasons in making switching from manual to electronic according to the interviewees includes the search functionality that EDMS offers, the search speed in accessing and using documents, the safety and reliability of the records kept with EDMS, and the time and monetary cost effectiveness of EDMS. 


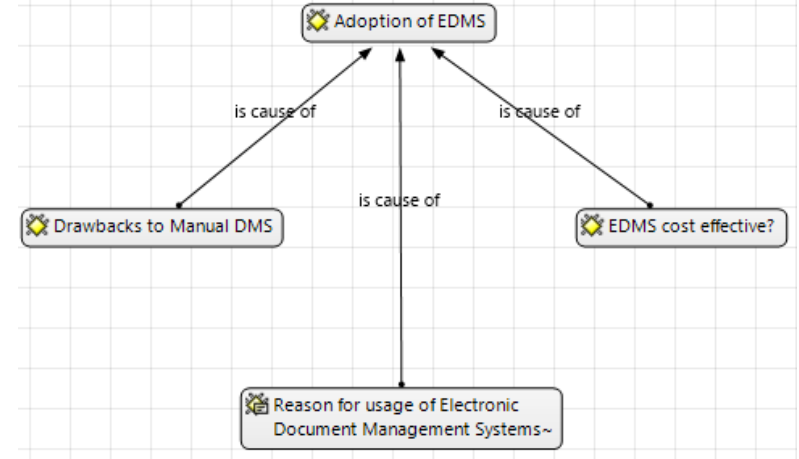

Figure 1: Adoption of EDMS

For instance, the following sections present the transcription of some of the respondents' comments when asked about the reason for EDMS adoption in their organizations:

"We moved over from manual document management to electronic because of the ability to search for document quickly and efficiently."

This comment indicates that manual record keeping and management is cumbersome and not efficient compared to the ability to index and search for documents with electronic document management system as established in [8]. In another response, another interviewee simply responded that:

"Our organization chooses EDMS because of its document Searching speed ability"

This is clear evidence that the search speed or the search functionality alone is a big part of what the businesses expect and enjoy from the application of the EDMS. Other important reasons for EDMS adoption as revealed are "document safety and reliability". A source responded as follows:

"We realized that we have some vital documents, these documents over time can be damaged, misplaced or affected. The only way we can get it safe is to index, scan and save them on our Google drive which we use a lot, and any time we need access, we just access them online"

Another respondent reckoned by saying:

"It (EDMS) can keep records intact for years, and it can be accessed anywhere with an internet connection"

This means, the safety of business records in electronic form is evidently a reason why EDMS is a preferred form of document management. Another reason for implementing EDMS may not necessarily come from the quality of the document management solution itself, but the limitations in which manual document solutions posed. An interviewee who employs manual document management laments as follows:

"We discontinue with manual document management because of its inefficiencies such as the time spent searching for documents, lack of funds to sustain the system, and the frequency of the times documents are retrieved"

This shows that manual record management is expensive and inefficient compared to when electronic document management system is used. This also relates to the submission of the findings in [3], [4] where features of EDMS were stated. Table 2 summarizes the five major emerged reasons for the adoption of various EDMS in businesses according to the analysis of the responses from the interviewees.

Table 2: Reasons for EDMS adoption in Ilorin Businesses

\begin{tabular}{cl}
\hline S/N & Reasons for EDMS adoption \\
\hline 1 & Search functionality \\
2 & Security Assurance \\
3 & Reliability \\
4 & Accessibility \\
5 & Cost effectiveness \\
\hline
\end{tabular}

Major Theme 2: Reasons for non-adoption of Electronic Document Management Systems.

The codes that make up this theme include "Barrier to implementing EDMS" and "Drawbacks to EDMS". This is represented in figure 2 as follows:

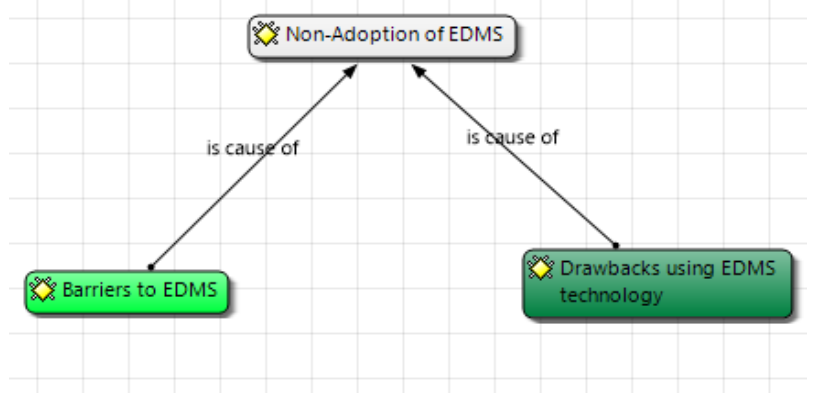

Figure 2: Non-adoption of EDMS

According to the responses from the interviewees, one of the prevailing reasons for non-adoption of EDMS is the inability of all organizations to fully implement EDMS in their operations, and thereby compelling organizations with the intention of switching to electronic management fully reverting back to manual system. A source stated as follows:

"Since these documents are electronic, we expect that when we need to relate with other organizations we can do so electronically, most 
organizations have not keyed into this EDMS, so we still have to print. It is like going back to where we came from."

Another interviewee complained that the files that are needed to be integrated into the EDMS between organizations have not been integrated, and it affects proper use of EDMS:

"The Integration of databases with documents needed for the running of the organization is not yet done".

This obstacle may restrict prospective EDMS users, in the sense that one of the major advantages of EDMS has been nullified by factors beyond what the organization can realistically control. This has to do with the available infrastructure and technology know how of the concerned organization.

Another reason that emerged from this theme is the concern that using electronic document management might make the organization vulnerable to fraudsters looking to beat the system. A respondent expressed the fear that a malicious insider with privilege access to pass key (codes) could steal easily from the organization without preventive measures. That interviewee is quoted saying:

"It is easy to perpetuate fraud if the attacker has the pass codes, unlike the manual that has different checks."

Though, the researchers believe that it is practically inaccurate to accept this notion, it is still very relevant because it expresses one of the serious concerns business owners have when thinking about employing EDMS or going digital. This relates to perceived risk of users as established in some information system theories such as modified UTAUT model in [3].

Similarly, a point worthy of note under this theme is the cost of the electronic document management solution been a barrier to the implementation of this technology. A source expressed the obstacle to the implementation of EDMS saying:

"Initially when we wanted to embark on EDMS we realized that going forward, we need some dedicated applications that can help us with indexing, storage, and easy access but purchasing of those applications is a "little bit" expensive, so we decided to do it in our own way, we scan and we sort and store by ourselves."

This limitation caused that organization to find alternative means to manage their documents electronically, the respondent further said:

"We had to improvise ourselves". The cost that is associated with launching this technology for the first time poses a barrier to organizations looking to implement it, especially to privately owned businesses that have limited purchasing power"

Another reason that emerged under this theme is the barrier that occurs from attempting to get staff of an organization move from the manual document management solution, to the electronic document management system. An interviewee cited this reluctance saying:

"Members of staff are lagging behind electronically and are not compliant and did not welcome the change."

This comment corroborates the findings from early studies such as $[1,5]$ that cited the poor digital literacy of members of staff as one of the reasons for this reluctance.

Another barrier that emerged from this theme is the epileptic nature of the internet service as a barrier to EDMS. An interviewee articulated that poor internet service hampers the usage of EDMS in the organization. When asked about the drawbacks to the usage of this technology, the source was quoted saying:

"Network Service Providers, network issues", The summary of the themes that emerged from the analysis of the responses of interviewees as barriers to the adoption of EDMS is given in table 3:

Table 3: Barriers to the adoption of EDMS

\begin{tabular}{ll} 
S/N & Barriers to EDMS Adoption \\
\hline 1 & $\begin{array}{l}\text { Other business associates are yet to fully } \\
\text { adopt EDMS }\end{array}$ \\
2 & $\begin{array}{l}\text { Document and database integration not yet } \\
\text { done }\end{array}$ \\
3 & $\begin{array}{l}\text { Fair of cyber-attack threat } \\
4\end{array}$ \\
$\begin{array}{l}\text { Cost implication of EDM solutions } \\
\text { (Expensiveness) } \\
5\end{array}$ & $\begin{array}{l}\text { Lack of computer literacy (knowledge) } \\
\text { Lack of infrastructural facilities (such as } \\
\text { internet and power supply) }\end{array}$ \\
\hline
\end{tabular}

Major theme 3: Choice of Document management solution.

The code that makes up this theme includes "Document management solution employed". Analyzing the interviewees' comments from this theme revealed that most Ilorin business organizations use Desktop computer, laptop Computer, scanner, printer, websites, email, payroll system, inventory management system, content management system (CMS), and database management system among

Vol. 38, No. 2, July 2019 
others. The finding also shows that most organizations use both electronic and manual means to manage their documents. For instance, when asked about their document management choice, a respondent was quoted saying:

"Both, but we use electronic most" However, it is worth noting that businesses in Ilorin have not fully embraced EDMS in their day to day business activities, but looking forward to taking advantages of electronic document management system if some of the challenges are ameliorated. The codes that emerged from the third theme which indicates the major EDMS solutions employed by most of the Ilorin businesses are summarized in table 4 thus: Desktop computer, laptop Computer, scanner, printer, websites, email, payroll system, inventory management system, content management system (CMS), and database management system among others.

Table 4: Ilorin Businesses EDMS Choice

\begin{tabular}{ll}
\hline S/N & Major EDMS Employs by Ilorin Businesses \\
\hline 1 & Desktop/Laptop computers \\
2 & Scanner and Printer \\
3 & Website, Social Networking Sites and Email \\
& Services \\
4 & Payroll System \\
5 & Inventory Management System (IMS) \\
6 & Content Management System (CMS) \\
7 & Database Management System (DBMS) \\
8 & Others \\
\hline
\end{tabular}

\subsection{Mapping of results to Information Systems Theories}

In order to validate the outcome of this study, the emerged codes (reasons) for the adoption and nonadoption of EDMS are mapped or cross-tabulated against the external factors (reasons) that determine users' adoption of technology as established in three popular information systems theories such as Technology Acceptance Model (TAM) [10], Unified Theory of Acceptance and Use of Technology (UTAUT) [11], and Theory of Planned Behavior (TPB) [12]. This is aimed at verifying the outcome of the proposed interpretive method against the state-of-the-art frameworks for investigating or predicting user acceptance or adoption of a technology like EDMS.

Briefly, In technology Acceptance Model (TAM), it is postulated that technology acceptance by users depends on some external factors such as perceived usefulness or benefits, perceived ease of use, attitude towards use and the intention to use [10]. In the Unified Theory of Acceptance and Use of Technology (UTAUT) framework as developed in [11] and modified in [3], it is assumed that the technology acceptance behavior of users depends on some external factors namely, performance expectancy, effort expectancy, social influence, facility condition, perceived value of record, perceived risk (under which we have, perceive risk, privacy risk, and overall risk). Theory of Planned Behavior (TPB) predicts the factors that determine the users' behavioral intention of using of a technology to include attitude, subjective norm, and perceived behavioral control $[5,12]$. These highlighted factors in the three identified theories are cross tabulated against the factors that determine the adoption and non-adoption of EDMS as emerged from this study.

The mapping or cross tabulation in table 5 shows that search functionality is one of the reasons that determine the adoption of EDMS and can be mapped to user perceived ease of use in TAM or effort expectancy in UTAUT. The theme revealed that users believe adoption of EDMS will make their works faster and more efficient. Also, Security assurance, reliability, accessibility, and cost effectiveness of EDMS are other factors that emerged as reasons that make EDMS adoption an ideal solution. These factors can be mapped to perceived usefulness or Performance expectancy as found in TAM and UTAUT models $[1,3]$. One of the reasons for non-adoption of EDMS by some organizations is as a result of the fact that other business organizations are not using it and thereby compelling them to revert to manual document management. This factor can be classified under societal influence as found in the UTAUT model. In addition, the non-integration of manual document with databases by various organizations as well as the epileptic power and internet services are also hampering the adoption of EDMS by some organization. These reasons can be categorized as facility condition of the organization as found in UTAUT framework.

Cyber-attack threat is another factor that affects the adoption of EDMS negatively. Some of the respondents believe that implementing EDMS may expose business data to attacks, with respect to the sophistication of cyber-attack nowadays. 
Table 5: Mapping of EDMS users' responses to Information System Adoptability factors

\begin{tabular}{|c|c|c|c|}
\hline $\mathrm{S} / \mathrm{N}$ & $\begin{array}{l}\text { Factors (themes) from Research } \\
\text { Analysis }\end{array}$ & $\begin{array}{l}\text { External Factors from Information Systems } \\
\text { Theories/ Models }\end{array}$ & $\begin{array}{l}\text { Adoptability } \\
\text { Category }\end{array}$ \\
\hline 1 & Search functionality & Perceived ease of use/Effort expectancy & \\
\hline 2 & Security Assurance & Perceived usefulness/Performance expectancy & \\
\hline 3 & Reliability & Perceived usefulness /Performance expectancy & Adoption \\
\hline 4 & Accessibility & Perceived usefulness /Performance expectancy & \\
\hline 5 & Cost effectiveness & Perceived usefulness/Performance expectancy & \\
\hline 6 & $\begin{array}{l}\text { Other business associates are } \\
\text { yet to fully adopt EDMS }\end{array}$ & Societal Influence (SI) & \\
\hline 7 & $\begin{array}{l}\text { Document and database } \\
\text { integration not yet done }\end{array}$ & Facility Condition & \\
\hline 8 & Cyber attack threat & Perceived Risk (privacy Risk) & \\
\hline 9 & $\begin{array}{l}\text { Cost implication of EDM } \\
\text { solutions (Expensiveness) }\end{array}$ & Perceived Risk (financial Risk) & Non-adoption \\
\hline 10 & $\begin{array}{l}\text { Lack of computer literacy } \\
\text { (knowledge) }\end{array}$ & Training & \\
\hline 11 & $\begin{array}{l}\text { Lack of infrastructural facilities } \\
\text { (such as internet and power } \\
\text { supply) }\end{array}$ & Facility Condition & \\
\hline
\end{tabular}

We can relate this factor to perceived risk with emphasis on privacy risk as in the modified UTAUT model [3]. Similarly, the cost implication of some EDMS makes adoption of electronic document management system difficult for some organizations to afford. This can also be mapped to perceived risk with an emphasis on financial risk.

Finally, the Computer literacy of users also determines the adoptability of the system. It was revealed that, users with no computer skills do not want the EDMS implemented in their organizations.

\section{DISCUSSION OF FINDINGS}

This study found "search functionality" as the central theme that determines the reason for the adoption of electronic document management system in Ilorin businesses. This indicates that effective search functionality is cogent in making the choice of the preferred document management solution. Other important reasons are "business data safety" and "reliability of the system". The ability of the system to providing needed services to users anywhere, at any time. The reason for adopting electronic document management may not be related to an inherent quality of the electronic document managements system alone, but due to the flaws in the manual document management system.

In contrast, one of the prevailing reasons behind nonadoption of EDMS in Ilorin businesses as revealed is the fact that many organizations are still transacting business manually. By not employing document management solutions forces other businesses that are desirous of using electronic document management revert back to manual processes like printing and dealing with papers when having to communicate with other organizations.

The perceived vulnerability in the electronic devices or system is another drawback to the use of EDMS according to the sample population. The fair of malicious insiders with pass keys and intrusion from the hackers (mostly from outside) are serious threat that concern the users. In addition, the cost that associates with the launching of the EDMS for the first time as well as the digital literacy level of most organization staff members remains a cogent reason that resists full adoption of EDMS solution.

Though, the deployment of both electronic and manual document management by organizations signaling slow adoption, it is an indication that the organizations will surely move from the cumbersome and expensive manual document management to the electronic system in a matter of time. The Ilorin business sphere has not fully embraced the software package that contains the full-fledged EDMS due to its cost, but is coming up with innovative ways to do the same. The reasons associated with the non-adoption of EDMS technology do not naturally stem from the EDMS itself, but its application and implementation in our own business sphere.

Electronic Document Management System within Ilorin metropolis businesses is still in its infancy, has teething problems which will soon be overcome as the technology becomes popular in the business sphere. For this reason, the barriers associated with the non- 
adoption of EDMS in Ilorin do not stem directly from the application itself, but an indication that the peripheral services of EDMS will get better with time. Fortunately, with the increasing availability of open source EDMS software, these obstacles would be overcome, and giving rise to the pervasion of this very useful technology in document management in the Ilorin business sphere. As established in the literature that technologies, when introduced to a business, will encounter issue that will be later resolved, and be accepted.

\section{CONCLUSION}

This study has examined the adoptability of electronic document management system in Ilorin businesses using an interpretive research method. Some of the factors that determine the adoption of EDMS as emerged in the themes include the search functionality, accessibility, reliability, and cost effectiveness of EDMS. The epileptic power supplies, poor internet service, security threats among others, are the major reasons for non-adoption of EDMS. The cross tabulation of the emerged factors against some state-of-the-art technology acceptance assessment models validates the outcome of the emerged factors from the study and confirms the appropriateness of the interpretive method.

\section{RECOMMENDATIONS}

Due to the factors that emerged as barriers to the adoption of EDMS in Ilorin business sphere, this study recommends an open source development of EDMS software to make it affordable to businesses. The agenda to move from manual filing system to electronic filing system should be championed by government and enforced on government institutions. As a result, the private businesses would follow suit in order to interoperate smoothly with the public sector. The epileptic nature of power in Ilorin metropolis should be addressed to make running of computers less expensive. The telecommunication companies should improve in their internet service delivery to enhance connectivity. The outcome of the result mapping with the external factors of some established IS theories shows that interpretive research method, UTAUT, and TAM are good frameworks for the assessment of the adoption and non-adoption of information systems such as EDMS. For future work, we plan to study the ways ubiquitous EDMS affects the Ilorin business sphere to enable businesses prepare for it, reap its benefits and anticipate its challenges.

\section{REFERENCES}

[1] K. Wijaya, B. Purwandari, and M. R. Shihab, "Personal Traits as Antecedents Towards Intention to Use: A Perspective of a Government EDMS Adoption in Indonesia," ICACSIS, pp. 183-188, 2015.

[2] N. Mehandjiev, U. Wajid, and A. Namoun, "Computers in Industry Designing and evaluating a system of document recognition to support interoperability among collaborative enterprises," vol. 64, pp. 598-608, 2013.

[3] A. A. Aziz, Z. M. Yusof, U. A. Mokhtar, and D. I. Jambari, "The Determinant Factors of Electronic Document and Records Management System (EDRMS) Adoption in Public Sector: A UTAUT-based Conceptual Model," 2017.

[4] N. Forcada, M. Casals, and X. Roca, "UP Commons," vol. 16, pp. 411-424, 2007.

[5] S. Hung, K. Tang, C. Chang, and C. Ke, "User acceptance of intergovernmental services: An example of electronic document management system," Gov. Inf. Q., vol. 26, no. 2, pp. 387-397, 2009.

[6] S. Jones, "International Journal of Information Management Government Document Management System: A case analysis of risk and reward," Int. J. Inf. Manage., vol. 32, pp. 396-400, 2012.

[7] P. Tyrvainen and T. Paivarinta, "On Rethinking Organizational Document Genres for Electronic Document Management," Proc. 32nd Hawaii Int. Conf. Syst. Sci., pp. 1-10, 1999.

[8] H. Zantout and F. Marir, "Document management systems from current capabilities towards intelligent information retrieval : an overview," vol. 19, pp. 471484, 1999.

[9] W. Satirah, W. Mohd, and A. Haider, "E-Court: Information and Communication Technologies for Civil Court Management," Proc. PICMET '13 Technol. Manag. Emerg. Technol., pp. 2296-2304, 2013.

[10] F. David, R. Bagozzi and P. Warshaw, "User acceptance of computer technology: a comparison of two theoretical models," Management science, 35 (8), 982-1003, 1989.

[11] V. Venkatesh, M. Morris, G. Davis, and F. Davis, "User acceptance of information technology: Toward a unified view," MIS quarterly, 425-478, 2003.

[12] I. Ajzen, "From intentions to actions: A theory of planned behavior. In Action control," Springer, Berlin, Heidelberg. 1985, Pp. $11-39$. 